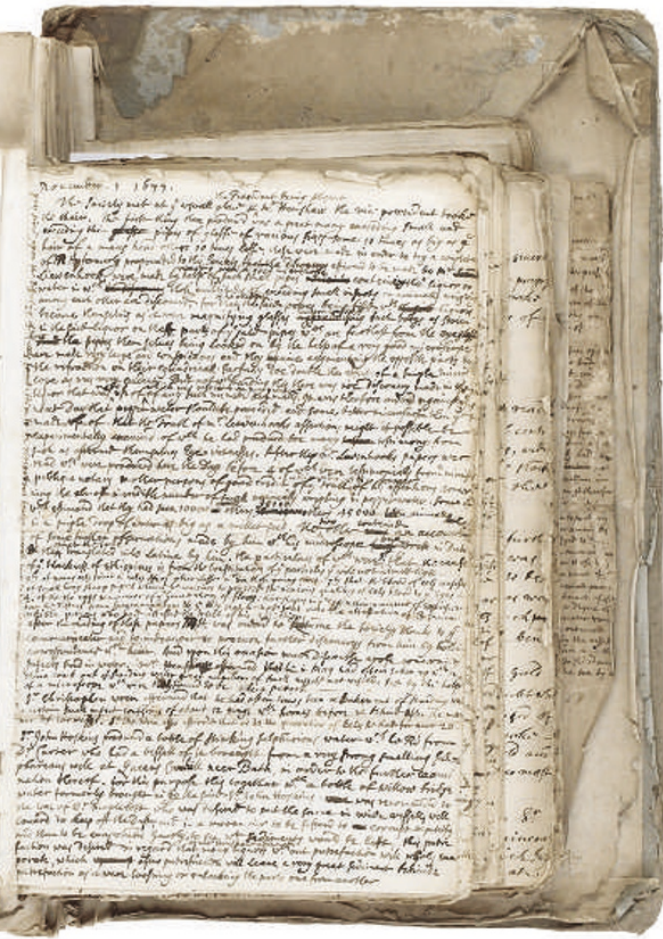

Jardine and others say it is vital that the manuscript remains accessible after its sale, so that it can be properly studied by science historians. But there is no guarantee that will happen. The Royal Society says it wants to bid for the documents, but lacks the funds. "I believe there is a lot of other serious stuff in there," says Jardine. "I'm desperate that it goes to an accessible home."

Should a foreign collector triumph in the auction, the UK government is likely to impose a three-month delay on issuing an export licence for the manuscript. Such a move would be designed to enable British museums to raise funds to mount a rival bid; UK law dictates that a museum could take possession if it matched the winning bid. Jim Giles

And some warn that other factors have been overlooked. Maria Wawer of Columbia University in New York, co-leader of a long-running study in Uganda, thinks deaths from AIDS play a role. Although prevention programmes deserve some credit, she says, "there's no reason to believe mortality is not contributing to this". After a decline in the late 1990s, HIV prevalence in Uganda now seems to be levelling off or even climbing back up.

The drop in Zimbabwe could also have been affected by violence and unrest, which have escalated there since 2000. Epidemiologist Christopher Beyrer of Johns Hopkins University in Baltimore, Maryland, says forced relocations and the departure of millions of young people seeking work may have skewed the study's results.

Erika Check

\title{
Possible planets left with no name
}

Astronomers trying to define a 'planet' won't announce a decision until August at the earliest, and may duck the issue entirely. In the meantime, researchers are left unable to name some newly discovered objects.

The issue was raised when astronomers led by the California Institute of Technology's Mike Brown reported finding objects that came close to Pluto in size, including Quaoar in 2002 and Sedna in 2004. It came to a head in July 2005, when the group announced the discovery of an even larger object, temporarily dubbed $2003 \mathrm{UB}_{313}$. Last week, scientists confirmed that this is substantially bigger than Pluto (F. Bertoldi et al. Nature 439, 563-564; 2006).

Until astronomers decide what counts as a planet, $\mathrm{UB}_{313}$ cannot be officially named. The International Astronomical Union (IAU) catalogues such objects, but different committees are responsible for naming major planets, and mere chunks of rock or ice. The indecision "really interferes with our work", says Brian

Marsden, head of the

Minor Planets Centre in

Cambridge, Massachusetts, which catalogues thousands of objects every year.

Brown's discoveries, 2005

FY9 and 2003 EL61, are also waiting to be named.

The IAU set up a 19-strong committee in 2004 to resolve the issue, which reported to the executive committee in November. Some experts suggested that anything spherical that orbits the Sun and is more than 2,000 kilometres across should be called a planet. That size limit would include Pluto and $\mathrm{UB}_{313}$, and was selected as "arbitrary but sensible", according to Iwan Williams, president of IAU's planetarysystems sciences division.

But other suggestions included stripping Pluto of its title, because thousands of objects occupy the same area of space, known as the Kuiper belt. "We should speak of eight major planets," says Marsden.

"People say schoolchildren will be upset, but so what? It's our job to educate them."
Others disagree. "Pluto is obviously a planet," says Alan Stern of the Southwest Research Institute in Boulder, Colorado, who heads the New Horizons mission that has just set off to Pluto. He argues that anything big enough to form a sphere as it orbits a star should be called a planet including the asteroid Ceres. This list could be broken down into categories such as 'terrestrial planet' or 'gas giant' (see Nature 437, 456-457; 2005).

The matter is now likely to be referred to the entire IAU membership at a meeting in Prague this August. Robert Williams, who sits on the executive committee, isn't optimistic about a resolution: "Nineteen experts wrestled with this for six months and didn't reach a conclusion." He favours waiting until more is known about the edges of our Solar System, and the planets around other stars. "My recommendation is we're not ready to move on this yet."

Mark Peplow

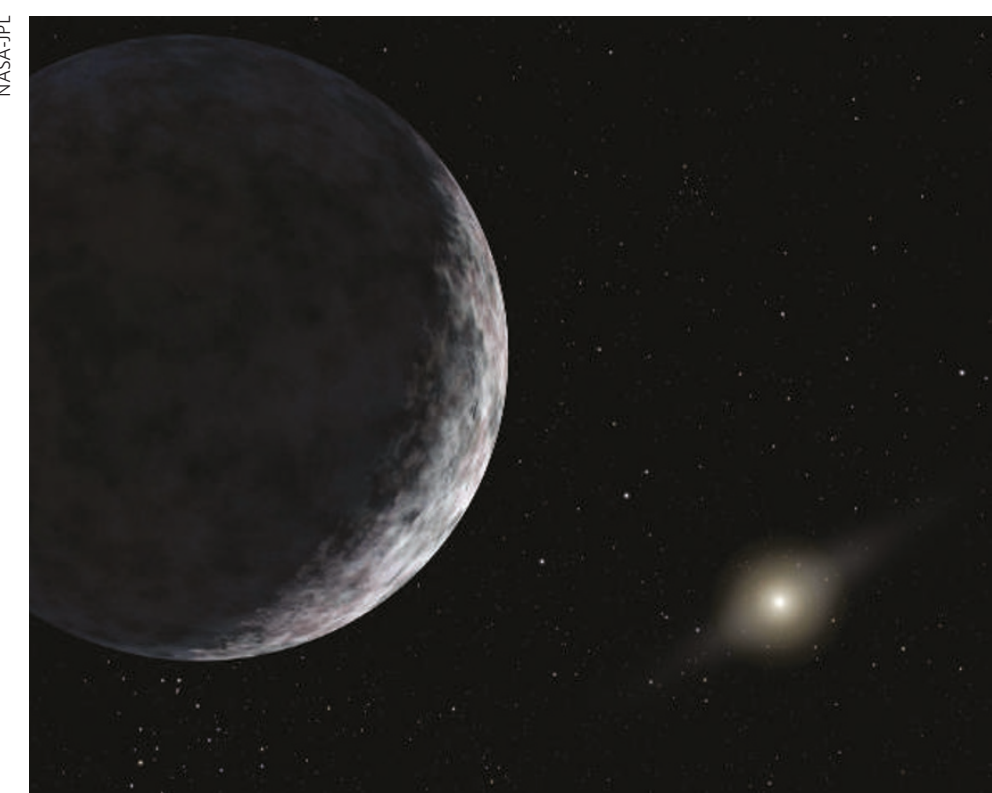

New arrival: $\mathrm{UB}_{313}$ is bigger than Pluto but hasn't yet been formally named because of indecision about its status. 